\title{
Tuning in to the Noise: Reconsidering Congressional Effectiveness
}

\author{
Collin Paschall, Johns Hopkins University
}

\author{
All views and opinions expressed in this article \\ are those of the author.
}

$\mathrm{O}$ ne of the most notable things for me when I first arrived on the Hill for my congressional fellowship in the Office of Representative Karen Bass was the noise. With nine desks in a single room no bigger than 400 square feet, it was unavoidable. Phones rang with folks on the line either asking for information I did not know or venting frustrations with my member about actions over which I had no control. Sometimes I had no choice but to hang up in response to an onslaught of racist or misogynistic invective. The staff in the office chatted about pop culture that passed me by in graduate school and Hill culture that was foreign to me. Advocacy group representatives stopped in for meetings, and the TV was on constantly. Evening receptions were packed, with "toothpick" food, sliders, veggie trays, and cookies serving as a critical nutritional subsidy for overworked and underpaid staffers. When I did get away from my desk, I had to learn to navigate through the tunnels that connect the buildings on the Capitol campus. The hallways were filled with stacks of desks and chairs, many from the offices of members who had lost in the last election. I got turned around in them just like the freshmen representatives, who you would occasionally see trying to find their way, similarly disoriented but more distinguishable by the pins on their lapels.

I started my fellowship on January 3, 2019, with Democrats in the House entering the year with pep in their step and newly returned to the majority. The specter of possible impeachment was present from the outset, and the government was shut down and continued to be shut down in the early going of the term. Neither of these were encouraging signs for partisan comity or legislative productivity. In the midst of

Collin Paschall, $P h D, J D$, is a faculty member in the Center for Advanced Governmental Studies at Johns Hopkins University. In 2019, he served as an APSA Congressional Fellow in the Office of Representative Karen Bass (D-CA). this, I set out with the dual purposes of fully immersing myself in the experience of working as a congressional staffer and trying to leverage the theoretical knowledge and research design acumen I developed in graduate school to better explain how the House of Representatives works.

As time passed and I became more accustomed to the routines of the office, I began to realize that while the noise is one of the features of congressional life, if you start to listen carefully you can pick out examples of the positive, ongoing work on Capitol Hill. In my first few meetings with policy advocates, I was impressed with their ability to answer questions and the wealth of resources they could provide. If I needed to come up to speed on a topic, I could get an expert from the Congressional Research Service on the phone often within the day. When I saw members interact with constituents and citizens with a stake in policy outcomes, it was obvious that the representatives were listening to and connecting with their audiences. Even in the annoyance that I saw between members when they disagreed in committee, I was witnessing the vigorous advocacy that is at the core of democratic deliberation. Spread throughout any day working in Congress, I saw plenty of such normatively encouraging activities.

Collectively, my experiences on the Hill underscored that while a legislative branch of a federal government is a political institution, Congress is a social enterprise, with members every day making loosely connected decisions while reacting to a wide array of social relationships and competing facts. Multiply by the network of staffers, support agencies, aligned interest groups, powerful constituencies, and other forces at play in the legislative process, and you have an organization with emergent characteristics stemming from millions of discrete actions. The strategic behaviors of 435 representatives and 100 senators are the foundation of the institution, but it reaches out far from there. While activity on the Hill may be bewildering to the public and frustrating for many observers, I found the resulting clatter appropriate for a diverse democracy of 330 million people.

Many critics today argue that Congress, as this chaotic web of relationships and information processing nodes, is overmatched by the challenges of governance. I felt similarly when I first sat down at my desk in the Rayburn House Office Building. I was concerned by the many findings that show Congress to be gridlocked, inefficient, and unproductive. As a firm believer in the primacy of the legislative branch, I was hopeful that I would be able to identify some feature of offices that made certain members more productive, effective lawmakers. Perhaps by identifying such practices, research like this might direct reform efforts that would help Congress reclaim some of its institutional power and work better for the American people.

My goal of trying to come up with ideas for congressional reforms was not original to me. The idea that Congress needs to be strengthened is very much in vogue today in Washington, DC. As I write this, the Select Committee on the Modernization of Congress has been renewed for a second year, and it has released 29 recommendations for how to improve congressional operations (Select Committee 2019). The APSA Task Force Project on Congressional Reform has generated a similar list (APSA 2019). The ideas advanced in the congressional reform community include transparency measures that would make it easier to see how members are voting and find out who is lobbying Congress. They would streamline human resources processes and increase pay for staff. The proposals suggest modernizing information technology systems and making activities more accessible to differently-abled Americans. There is also some discussion about making more significant changes like switching to twoyear budgets and finding ways to reform 
campaign finance that reduce the tremendous time burden that fundraising places on members.

These kinds of reforms would substantially improve the quality of life of members of Congress and their staff. The staff I know are overworked and underpaid. There is an extremely minimal degree of human resources support and training. Turnover is too high, with permanent staff often finding it financially impossible to stay in their jobs in the long run and offices over-relying on temporary detailees and fellows like me who are there for only a few months or a year. There are also many clunky administrative processes that waste staff time and could be improved with better information technology systems. The most outstanding example from my short tenure on the Hill is the appropriations letter process, a grueling several weeks in the spring when staffers and interns roam around the Hill collecting hundreds of inked signatures from offices simply to ask for plus-ups on items in the appropriations bills. Our interns and occasionally staff were quite literally walking 10 miles in a day across the House buildings as part of this archaic process.

It is also clear that Congress needs more resources for oversight. It is true that investigations are frequently used as political cudgels, and I am worried that more resources would be used to harass the executive in politically expedient ways. However, there are still good reasons for Congress to be properly resourced for its work overseeing the administrative state. I accept there will be some "bad" investigations, but there is enough value in the "good" ones to justify supporting this activity at a scale commensurate with the vastness of the federal government and the scope of its activities. As it currently stands, many staff members are trying to multitask their investigative work and their legislative work, when both of these could easily be full-time obligations.

As these views suggest, I maintain some of the perspective I carried into my time in Congress. Providing more resources might smooth some of the sharp corners of the legislative process, perhaps facilitating improvements in institutional efficacy. The kinds of reforms being proposed are inexpensive, such that even if the downstream benefits are somewhat speculative, it is surely worth it to make such a marginal investment.

So, if I am still in support of the congressional reform movement, what changed after my fellowship? As I reflect on it, I would say the greatest shift in my thinking was in my sense of the distance between the floor and ceiling of congressional effectiveness. In terms of the floor, I am convinced that Congress is getting a bit of a bad rap. My observation is that the institution, even in an arguably reduced state, retains a great deal of legislative capacity. In any given week, there are dozens and dozens of briefings on the Hill and nearby in Washington, DC, that connect members and staff with the information they need to do their jobs. The information ecosystem that Congress has access to, in terms of interest groups, think tanks, and academics, is very rich. To use myself as an example of how easy it is for staffers to get policy information, I was tasked with supporting my boss's work related to criminal justice reform. I knew relatively little about this topic at the start of the fellowship, but I quickly discovered that I could get access to resources that could get me up to speed. Advocates were happy to provide in-person briefings upon request, and I was able to get on the phone with a wide range of experts on this issue. Within a couple of months, I felt that I had a reasonably good grasp of the major controversies and issues facing Congress related to criminal justice reform.

While my academic training helped me develop strong research skills, I was not unique on the Hill in being a savvy information consumer. Many congressional staff arrive with strong educational and professional credentials (Burgat and Billing 2019), and while members and staffs may not have true expertise in every issue over which they are responsible, they certainly have enough knowledge and political skill to discriminate between options that are presented to them. Political actors have developed efficient ways of providing Congress with information, and when it is necessary to go on a deep dive on a particular topic, members and staff have the ability to do that.

Just look at the bills labeled H.R. 1 through 10, all of which are specially reserved for the majority's priority agenda items, and you will see large, wellresearched, and carefully crafted pieces of legislation. There are still extensive negotiations among outside groups, members, and leadership about what goes into these bills, and this is even after the turn we have seen across time towards party leadership taking a strong hand in assembling legislative packages (Curry 2015). The larger point is that pieces of legislation like this represent the culmination of a significant amount of expertise, throughout the Hill, around town, and across the country. Much of this effort is missed though, because these bills are unlikely to become law during divided government and some may not even be passed by the House.

This gets at my other major takeaway from being on the Hill. My view after witnessing the legislative process firsthand is that, even if Congress could be optimally staffed and resourced, the tension between the legislative and representative functions of Congress would significantly restrain the ability of the institution to make law. There is a lot of political disagreement on the Hill about preferred outcomes, both across and within parties. I saw this firsthand by staffing a member who worked on the Judiciary Committee and sitting in on some of the hearings following up on the Mueller investigation. But beyond those theatrics, there is assuredly a very serious gap between the Republican and Democratic parties, representing a face-off between what Ron Brownstein has characterized as coalitions of "restoration" and "transformation" (Brownstein 2012; Brownstein 2016).

Even beyond such inter-party clashes, intra-party skirmishes still reflect a wide diversity of opinion. While co-partisan representatives may generally agree with one another about the direction of policy on most issues, the parties are not unitary actors by any stretch (Curry and Lee 2019). Most Democratic members would probably agree that access to health care should be expanded, but it is obvious from looking at the 2020 presidential primaries-whose dynamics are reflected in Congress-that there is little Democratic consensus about how to do this. Similarly, among Republicans, I saw real divides about what to do about criminal justice reform and the issue of the Trump administration's trade and foreign policy. The two parties look coherent when placed in opposition to one another, but looking at either individually, the rifts can be seen clearly enough. This amounts to a serious obstacle to making federal policy, so much so that it restricts what Congress could accomplish with the resources it already has at its disposal.

If I am right that the biggest factor limiting Congress is the political dynamics that vivify Capitol Hill, I suppose there are several conceivable ways to respond to this. One would be to try to lower the 
temperature of partisan conflict through some set of institutional rule changes that force members to build relationships and work together. But, I have my doubts about these kinds of efforts, because I do not see the incentive for members to foist such measures upon themselves at the risk of compromising their policy goals. A second approach would be to try to tamp down the level of partisanship at the extreme edges of the electorate, perhaps through more civic education programming and having members of Congress try to reach out more to citizens who are disengaged or even did not vote for them. As with trying to get members to go to more cocktail parties with one another, though, I am not sure why legislators would submit themselves to such treatments, especially when so many are in electorally secure districts.

The third alternative is recalibration and stoicism. I newly appreciate that Congress is in equal parts a representative and legislative institution, and that right now the representative functions of Congress give voice to an electorate that has fractured perspectives on many policy questions. To that extent, congressional dysfunction is reflective of the character of a changing nation, where policy imperatives have not driven the public to legislative consensus. It is reasonable to hope that congressional reforms might help Congress complete some of its more routine tasks, like keeping the government operating (Haskell 2019). However, the quality of American democracy right now is contentious, and Congress sits at the center of this.

During my stint on the Hill, I participated in or was in close proximity to nearly every activity a legislative staffer would engage in during the first three to five years of his or her career on the House side, starting as an intern and moving up towards becoming a legislative director. Fenno wrote that "immediate proximity to data... produces sensitivities that give observation 'value added"' (Fenno 1986). For me that value added led to a shift in my thinking about congressional effectiveness, based on a holistic evaluation of all of the evidence I saw while I was an observerparticipant. I have great respect for those serving the American people in congressional offices. They work really hard, they are highly skilled, and they have a tough job ahead of them.

\section{REF E R E N C E S}

American Political Science Association. 2019. "Report of the Task Force Project on Congressiona Reform." https://www.legbranch.org/app/ uploads/2019/11/APSA-Congressional-ReformTask-Force-Report-11-2019-1.pdf.

Brownstein, Ronald. 2012. "The Coalition of Transformation vs. the Coalition of Restoration." The Atlantic. https://www.theatlantic.com/politics/ archive/2012/11/the-coalition-of-transformationvs-the-coalition-of-restoration/265512/.

Brownstein, Ronald 2016. "Donald Trump's Coalition of Restoration." The Atlantic. https:// www.theatlantic.com/politics/archive/2016/o6/ donald-trumps-coalition-of-restoration/488345/.

Burgat, Casey and Trey Billing. 2019. "Everything You've Ever Wanted to Know About Educational Pipelines to Capitol Hill." LegBranch.org. https://www. legbranch.org/everything-youve-ever-wanted-toknow-about-educational-pipelines-to-capitol-hill/.

Curry, James. 2015. Legislating in the Dark: Information and Power in the House of Representatives. Chicago University Press.

Curry, James and Frances Lee. 2019. "Non-Party Government: Bipartisan Lawmaking and Party Power in Congress." Perspectives on Politics 17 (1): 47-65.

Haskell, John. 2019. "Congressional Reform Without the Ideology." LegBranch. org. https://www.legbranch.org/ congressional-reform-without-the-ideology/.

Fenno, Richard. 1986. "Observation, Context, and Sequence in the Study of Politics." American Political Science Review 80 (1): 3-15.

Select Committee on the Modernization of Congress. 2019. "Recommendations." https:// modernizecongress.house.gov/committee-activity/ recommendations. 